\title{
Introducing studio oriented learning environment (SOLE) in UPM, Serdang: accessing student-centered learning (SCL) in the architectural studio
}

\begin{abstract}
ABSTRCT
This article reports the initial results of the exploratory research related to student-centered learning (SCL) in final year Architecture studio education in Universiti Putra Malaysia (UPM). SCL is defined as an approach to empower students in their own learning. Although studies on the adaptability of this concept in education has increased, there are few studies conducted for the benefits of architectural education from studio design perspective. In this article, we define SCL as an approach to increase student autonomy in learning curve especially in making decisions related to design subjects using a summative and formative approach. The objective of this article is to experiment the SOLE model and how it can move forward. The SOLE (Studio Oriented Learning Environment) model encompasses lecturing, sharing and peer review that is inspired by self-regulated theory. However, several problems and difficulties were identified namely, a lack of tutor input and problems in discussion dynamic in addition to resistance to peer assessment. This article suggests a number of improvements for future recommendations. The study will benefit educators in the architectural field in contributing to helping students to build on unique background knowledge and at the same time let the students generate learning opportunities and reconstruct knowledge dynamically in an open-ended learning environment to implement SCL in the studio module.
\end{abstract}

Keyword: SOLE architectural education; Peer review; SCL; Architectural pedagogy. 